\title{
Introduction to the Creativity in Teams and Organizations Minitrack
}

\author{
Triparna de Vreede, GJ de Vreede \\ Information Systems \& Decision Sciences Department \\ University of South Florida \\ tdevreede@usf.edu,gdevreede@usf.edu
}

\author{
Isabella Seeber \\ Department of Information Systems, Production and \\ Logistics Management \\ University of Innsbruck, Austria \\ isabella.seeber@uibk.ac.at
}

Innovation is a critical force in organizational performance and survival. Changes in technology, globalization, and increased competition have all created an environment in which creativity and innovation are needed in order to cope with situational and economic pressures and frequent changes. Designers and developers of organizational systems must therefore innovate almost continuously to keep the organization aligned with such changes. Creativity is a critical pre-condition for innovation. Generating novel and creative ideas are the key to innovation and growth in every organization today. Providing employees with tools to think creatively has proven to increase innovation in organizations. Research shows that organizations that have established skill-bases and tools for creativity outperform the competition in terms of revenue, rolling out new products, innovation and growth. Though organizations deploy groups for most creative processes, there has been little research in the area of group creativity. Most creativity research focuses on individual factors affecting creativity. Many challenges that arise from pursuing creativity in teams remain unexplored. Consequently, it is important that creativity in teams are given a central place in organizational research.

The topic of creativity has been a constant feature of the HICSS conference from HICSS-28 to HICSS-36 and HICSS-38, and HICSS-42 to HICSS-52. The minitracks on Creativity have been highly successful, attracting a significant number of submissions and participants at the conference. At HICSS-43, HICSS-49, and HICSS-51, a paper from the Creativity minitrack was honored as the best paper in the Collaboration Systems and Technologies Track.
The earliest creativity minitracks at HICSS focused on creativity in IS functions and organizations. Many of the paper contributions in these earlier minitracks studied creativity on an individual level. Since HICSS-42, the minitrack also includes research that focuses on creativity at a group and organizational level. In the recent years, even a societal level treatment of creativity has emerged in the form of crowdsourcing as a vehicle to develop creative ideas, products, and services. We expect the topic of creative crowdsourcing to grow in attention in the years to come. In addition, we recently have witnessed a re-emergence of research on creativity technologies, which puts creativity research at the heart of the socio-technical focus of the HICSS conference.

This year's minitrack features three papers that address a variety of creativity-related topics:

- Creativity Loading - Please Wait! Investigating the Relationship between Interruption, Mind Wandering and Creativity, by Thorben Lukas Baumgart, Michael Klesel, Frederike Marie Oschinsky, and Bjoern Niehaves

- Creativity Is Connecting Things: The Role of Network Topology in Fostering Collective Creativity in Multi-Participant Asynchronous Online

Discussions, by Noa Sher, Carmel Kent, and Sheizaf Rafaeli

- Understanding how Digital Intelligence contributes to Digital Creativity and Digital Transformation: A Systematic Literature Review, by Imed Boughzala, Mahda Garmaki, and Olfa Chourabi Tantan 